\title{
Memória e produção social da informação em direitos humanos: uma perspectiva latino-americana
}

\author{
Maria Guiomar da Cunha Frota ${ }^{I}$ \\ https://orcid.org/0000-0002-5323-1879 \\ ${ }^{I}$ Universidade Federal de Minas Gerais, Belo Horizonte, MG, Brasil. \\ Doutora em Sociologia pelo IUPERJ (Sociedade Brasileira de Instrução - 2004). \\ Mestre em Sociologia pela Universidade Federal de Minas Gerais (1995). \\ Graduada em História pela Pontifícia Universidade Católica de Minas Gerais \\ (1988). Professora associada da Universidade Federal de Minas Gerais - Escola \\ de Ciência da Informação.
}

http://dx.doi.org/10.1590/1981-5344/3900

O artigo trata das relações entre memória e produção social da informação em direitos humanos à luz de uma perspectiva teórica latino-americana. No plano teórico apresenta uma perspectiva latino-americana sobre o tema e considera que esta perspectiva tem como antecedente e suporte uma extensa produção de informação sobre direitos humanos por organizações não-governamentais. No plano empírico avalia a produção acadêmica em Ciência da Informação sobre documentos e arquivos de direitos humanos, repressão e a resistência.

Palavras-chave: Memória. Informação. Direitos humanos. América Latina. Ditadura.

The article deals with the relations between memory and the social production of human rights information's in the light of a Latin American theoretical perspective. On the theoretical level, it presents a Latin American perspective on the subject and considers that this perspective has as antecedent an extensive production of human rights information's by nongovernmental organizations. At the empirical level evaluates the academic production in Information Science about documents and archives of human rights, repression and resistance.

Keywords: Memory. Information. Human rights. Latin America. Dictatorship. 


\section{Introdução}

Pretende-se nesse artigo tratar das relações entre memória e produção social da informação em direitos humanos à luz de uma perspectiva teórica latino-americana.

Na Europa, após a eclosão da segunda guerra mundial, configuramse perspectivas teóricas, como a teoria crítica e a as teorias da pósmodernidade, marcadas pelo legado de destruição e de violência dos regimes nazistas e fascistas e pela desilusão com os processos de racionalização da modernidade. Naquele contexto político e intelectual europeu, o tema da memória e da dialética entre Memória e História ganhava relevância ${ }^{1}$.

Na América Latina, e mais especificamente no Cone-Sul, o tema da memória alcança relevância principalmente a partir da eclosão das ditaduras militares e dos movimentos de resistência e de luta contra as violações direitos humanos perpetradas por essas ditaduras (no Chile de 1973 a 1989, no Uruguai de 1973 a 1985, na Argentina de 1976 a 1983, no Paraguai de 1954 a 1989 e no Brasil de 1964 a 1985).

Assim no plano teórico o artigo parte da perspectiva de que os autores latino americanos fundamentam suas construções sobre o tema da memória social, sobretudo nos autores europeus do pós-guerra mas, ao problematizarem essa literatura à luz do contexto sócio-político da região, propõem novas possibilidades interpretativas e chaves de leitura.

A partir dessas novas possibilidades interpretativas pretende-se problematizar as relações entre memória e produção social da informação relativa aos direitos humanos, a repressão e a resistência.

O artigo está organizado em três tópicos: a) memória e lutas sociais em uma perspectiva latino-americana, b) memória e produção social da informação em direitos humanos e c) considerações finais.

\section{Memória e lutas sociais: uma perspectiva latino americana}

Nas ciências sociais e humanas o tema da memória social se configura a partir do início do século $\mathrm{XX}$, impulsionado principalmente pelo trabalho de Halbwachs que, pioneiramente, delineou a memória como um objeto social resultante dos processos de constituição de identidades dos sujeitos a partir de sua inserção em grupos sociais.

Após a segunda guerra, como já mencionado na introdução, o tema da memória se expande. Não cabe ao escopo do artigo uma revisão exaustiva da literatura europeia, são mencionadas apenas concepções e conceitos de autores que se considera chaves para a posterior análise da perspectiva latino-americana.

\footnotetext{
${ }^{1}$ Para uma análise dessa produção sobre memória ver SANTOS (2003).
} 
Pierre Nora, partilhando do referido contexto de crise da modernidade e da consciência da ruptura com o passado, elabora o conceito de lugares de memória, significando algo concebido a partir "do sentimento que não há memória espontânea e que é preciso organizar arquivos, atas e celebrações." (NORA, 1993, p. 13). Essa ruptura com o passado é caracterizada pelo autor como uma passagem da memória que ele define como "memória verdadeira, social, inscrita no corpo" para a memória transformada em passagem à história, que "precisa de um suporte, memória do papel, das bases de dados, produtora dos arquivos." (NORA, 1993, p. 14)

Ao analisar a relação entre Memória e História Paul Ricoeur faz a seguinte indagação: "A narrativa, a história é o remédio ou o veneno do lembrar e da memória? A resposta aponta para uma dialética do esquecimento- "a arte de narrar provoca o esquecimento e o discurso é uma imagem daquilo que na memória é vivo". (RICOEUR, 2007, p. 153)

Ricoeur argumenta que a memória viva, o testemunho, antecede o documento, o arquivo e a história e ressalva que:

[...] não temos nada melhor que o testemunho em última análise, para assegurar-nos de que algo aconteceu, a que alguém atesta ter assistido pessoalmente, e que o principal, se não às vezes o único recurso, além de outros tipos de documentação, continua a ser 0 confronto entre testemunhos. (RICOEUR, 2007, p. 156).

A força do testemunho reside no seu vínculo com o sujeito narrador, esse se apresenta como alguém que presenciou o acontecimento, que vivenciou ou foi vítima daquilo que narra. Mas, argumenta Ricoeur (2007), a credibilidade da narrativa, em um primeiro plano, depende de quem ouve, de quem recebe, se opõe ou se identifica com os testemunhos e os testemunhantes. Em um segundo plano, nas operações historiográficas ou jurídicas, o testemunho é inscrito nos documentos e também contraposto aos documentos de arquivo e aos outros vestígios não escritos e não orais do passado.

Na perspectiva de Pollak os atores sociais e seus testemunhos são centrais para a memória e a história, principalmente por fazerem emergir memórias subterrâneas.

Ao privilegiar a análise dos excluídos, dos marginalizados e das minorias, a história oral ressaltou a importância de memórias subterrâneas que, como parte integrante das culturas minoritárias e dominadas, se opõem à 'memória oficial', no caso a memória nacional. Num primeiro momento, essa abordagem faz da empatia com os grupos dominados estudados uma regra metodológica e reabilita a periferia e a marginalidade. Ao contrário de Maurice Halbwachs, ele acentua o caráter destruidor, uniformizador e opressor da memória coletiva nacional. Por outro lado, essas memórias subterrâneas que prosseguem seu trabalho de subversão no silêncio e de maneira quase imperceptível afloram em momentos de crise em sobressaltos bruscos e exacerbados. A memória entra em disputa. (POLLACK, 1989, p. 4) 
Para Pollack, portanto pelas memórias sociais se acede ao que estava oculto pela narrativa oficial nacional.

As concepções europeias sobre memória têm uma influência importante sobre a literatura latino-americana, mas são reinterpretadas, dentre outros aspectos, à luz de uma característica marcante na região e mais especificamente do Cone Sul. No Cone-Sul a produção governamental e a acadêmica sobre memória foi antecedida por uma extensa produção social dos grupos de direitos humanos, bem como das vítimas sobreviventes da repressão ocorrida durante as ditaduras militares. Para sustentar o argumento mencionam-se dois casos relevantes.

No Brasil uma extensa documentação, extraída dos processos dos tribunais militares, foi reunida no projeto Brasil Nunca (BNV) desenvolvido, nos anos oitenta em plena ditadura, por organizações religiosas- o Conselho Mundial de Igrejas e a Arquidiocese de São Paulo, sob a coordenação do Rev. Jaime Wright e de Dom Paulo Evaristo Arns. O projeto resultou em um relatório de 1000 páginas e na publicação de um livro (em 1985) que teve ampla repercussão, conforme se contata pelo número de reimpresssões e edições:

[...] o livro foi reimpresso vinte vezes somente nos seus dois primeiros anos de vida, tendo já ultrapassado a marca de 40 edições. Permaneceu na lista dos dez mais vendidos por 91 semanas consecutivas, tornando-se - à época - o livro de nãoficção brasileiro mais vendido de todos os tempos.(SOBRE..., 2016).

O acervo documental do Projeto BNM tem sido amplamente utilizado por todas as comissões oficiais de apuração de violações de direitos humanos ocorridas durante a ditadura: a de mortos e desaparecidos (1995), a de anistia (2002) e a da verdade (2011). A referência a documentação de todas essas organizações não governamentais também está presente em parte significativa da literatura acadêmica brasileira nos campos da história, do direito e da arquivologia. ${ }^{2}$

Na Argentina a documentação reunida por várias organizações não governamentais: Asamblea Permanente por Derechos Humanos (APDH), Liga Argentina por los de Derechos del Hombre (LADH), dentre outras, foi amplamente utilizada pela Comissão Interamericana de Direitos Humanos, em 1979 e pela Comission Nacional sobre la desaparicion de personas (CONADEP), em 1983.

A reconstituição das memórias da repressão, após as ditaduras militares no Cone Sul, é um processo conflituoso, de lutas e disputas entre atores e grupos, que resultam em múltiplas interpretações sobre o passado. Conforme Jelin (2002) nesse plano de disputas pela

\footnotetext{
${ }^{2}$ Não é possível no escopo do artigo quantificar e nem sistematizar essas publicações acadêmicas, no entanto cita-se que em uma busca livre no google acadêmico com o termo Brasil Nunca Mais resulta em 590.000 citações. A base Brasil Nunca Mais on-line teve 4.302.351 documentos acessados apenas entre agosto de 2017 e novembro de 2018, ver BMN Digital. Disponível em: http://bnmdigital.mpf.mp.br/pt-br/. Acesso em: 13 dez. 2018.

${ }^{3}$ Sobre a CONADEP e a participação das organizações não-governamentais ver CRENZEL (2014) e CONADEP (2014).
} 
ressignificação do passado estão incluídas visões e perspectivas políticas para o futuro.

El escenario político es de cambio institucional en el Estado y en la relación Estado-sociedad. La lucha se da, entonces, entre actores que reclaman el reconocimiento y la legitimidad de su palabra y de sus demandas. Las memorias de quienes fueron oprimidos $y$ marginalizados, en el extremo- quienes fueron directamente afectados en su integridad física por muertes, desapariciones forzadas, torturas, exilios $y$ encierros- surgen con una pretensión, la de dar la versión "verdadero" de la historia a partir de su memoria y la de reclamar justicia. En esos momentos memoria, verdad y justicia parecen confundirse y fusionarse, porque el sentido del pasado sobre el que se está luchando es, en realidad, parte de la demanda de justicia en presente. Son momentos en los que emergen públicamente relatos y narrativas que estuvieron ocultos y silenciados por mucho tiempo. (JELIN, 2002, p. 42, grifo nosso).

Essa dimensão conflituosa da ressignificação também é apontada por Beatriz Sarlo quando ela analisa criticamente o peso do testemunho e da guinada subjetiva na reconstituição do passado e na afirmação das memórias coletivas:

O passado é sempre conflituoso. A eles se referem, em concorrência, a memória e a história, porque nem sempre a história consegue acreditar na memória e a memória desconfia de uma reconstituição que não coloque em seu centro os direitos da lembrança (direitos de vida, de justiça, de subjetividade). (SARLO, 2007, p. 9)

Sarlo propõe que "qualquer relato de experiência é interpretável" e que, portanto, não é suficiente lembrar é preciso um esforço de compreensão. Assim os testemunhos devem ser emoldurados, situados em relação ao contexto ideológico e político que procuram reconstituir.

As memórias sociais em disputa repercutem sobre o plano da elaboração das políticas de memórias que, no Cone Sul, vem sendo constituídas, sobretudo a partir da década de 1990, em ritmos e com características próprias em cada país. Nora Rabotnikof (2006), em uma publicação destinada a pensar os 30 anos do golpe na Argentina, elabora uma distinção conceitual entre memórias da política, aquelas narradas pelas vítimas e seus contemporâneos e as políticas de memória construídas no plano institucional:

Por memorias da política nos referimos a las formas y narraciones a través de las cuales los que fueran contemporáneos de un periodo construyen el recuerdo de ese pasado político, narrando sus experiencias y articulan, de manera polémica, pasado, presente y futuro. $Y$ también a las imágenes de la política que aquellos que no fueron contemporáneos construyen de ese pasado a partir de los testimonios, recuerdos, documentos. O sea, a las memorias de otras memorias. Por políticas de memoria, en cambio, aludimos a las formas de gestionar o de lidiar con ese pasado, a 
través de medidas de justicia retroactiva, juicios históricos-políticos, instauración de conmemoraciones, fechas y lugares, apropiaciones simbólicas de distinto tipo. Pero por políticas de la memoria también se hace referencia aquí a 'las grandes ofertas de sentido temporal', o las narrativas más generales, que proponen marcos institucionales (y están implícitas en ellos), construyen temporalidades diferentes y de ese modo contribuyen a marcar continuidades y rupturas. (RABOTINIKOF, 2006, p. 260, grifo nosso).

Destaca-se que nessa definição a autora concebe as políticas de memória não apenas como uma forma de gestão do passado, mas como "ofertas de sentido, grandes narrativas" e que, portanto, tem implicações no plano interpretativo.

À luz dessas perspectivas interpretativas postas pelos autores latino-americanos é que se propõe uma sistematização sobre a produção social da informação em direitos humanos no campo da Ciência da Informação.

\section{Produção social da informação em direitos humanos: problematização e possibilidades de investigação}

A informação produzida por organizações de direitos humanos internacionais, regionais e nacionais e por organizações repressivas do aparato ditatorial tem subsidiado a formulação, implementação e monitoramento de políticas de direitos humanos, resultante de tratados e convenções internacionais, bem como políticas no campo da memória, verdade e justiça em contextos transicionais, pós-ditatoriais, no cone sul.

Os documentos e informações desse amplo campo que genericamente denominamos produção documental em direitos humanos têm ainda subsidiado e impulsionado a produção científica em distintos campos do conhecimento. Nesse artigo se enfoca mais especificamente a produção da Ciência da informação, da Biblioteconomia e da Arquivologia em diálogo como a história e o direito. Os temas e questões de pesquisa apresentados versam sobre: 3.1) relatórios e publicação em direitos humanos: fluxos documentais, bibliometria e tesauros; 3.2) testemunhos e documentos da repressão e da resistência.

\subsection{Relatórios e publicações em direitos humanos}

Os relatórios produzidos por organismos internacionais de direitos humanos para monitorar a implementação de convenções internacionais são fontes relevantes de pesquisas para a Ciência da Informação. Tratam-se de pesquisas que têm como desafio reconstituir os fluxos informacionais incluindo todo o processo de produção e de circulação de informação sobre o amplo campo dos direitos humanos. Para um mapeamento inicial citam-se as produções relativas às seguintes temáticas: 
a) informação para o monitoramento da Convenção de Direitos da Criança na ONU e no sistema interamericano (FROTA, 2008; FROTA; QUINTÃO, 2007; FROTA; BARBOSA NETO, 2011; FROTA, 2011; FROTA; BARBOSA NETO, 2013; FROTA, 2014);

b) fluxos informacionais para monitoramento da Convenção Sobre as Piores formas de trabalho infantil (BARBOSA NETO, 2013);

c) análise bibliometrica da Sur Revista Internacional de Direitos Humanos (RIBEIRO, 2016; RIBEIRO; FROTA, 2017);

d) qualidade do tesauro da Corte Interamericana de Direitos Humanos (FROTA; RIBEIRO; GOMES, 2017).

Essas pesquisas possibilitam uma compreensão dos processos de produção, de seleção, de classificação e de organização das informações por distintas organizações, instâncias e níveis de governo e também dos processos de circulação, de organização e de disponibilização da informação e das publicações sobre direitos humanos.

\subsection{Testemunhos e documentos da repressão e da resistência}

Durante a vigência das ditaduras militares no Cone Sul paralelamente à produção de documentos oficiais pelos órgãos de informação e de repressão (como o Serviço Nacional de Informações, no Brasil e a Dirección de Inteligencia de la Policía de la Provincia Buenos Aires) ${ }^{4}$ foram reunidos, por organizações de direitos humanos, nacionais e internacionais, acervos compostos sobretudo por listas de denúncias de desaparecimentos, relatos de vítimas sobreviventes da tortura e da perseguição e de familiares de mortos e desaparecidos.

Após o termino das ditaduras, especialmente a partir de 1980, emergiram então com distintos formatos e percursos em cada país, processos de disputa e de lutas sociais em torno da configuração das memórias da repressão e da resistência. De um lado as memórias dos resistentes e das vítimas da ditadura, de seus familiares e de organizações de direitos humanos, de outro lado, as memorias dos militares, nas altas patentes em formato de livros ou entrevistas para jornalistas e historiadores, sobretudo aqueles envolvidos em projetos de história oral e, nas baixas patentes, na forma de entrevistas para revistas de circulação nacional. Naquele contexto o campo das ciências sociais foi marcado por uma extensa produção problematizando relações entre

\footnotetext{
${ }^{4}$ Sobre o SNI ver ALVES (1984) e sobre a DIPBA ver COMISION PROVINCIAL POR LA MEMORIA/ARQUIVO DIPBA. Disponível em: http://www.comisionporlamemoria.org/cuadroclasificacion/\#seccion12. Acesso em: 13 dez. 2018.
} 
ditadura, resistência e memória e a Ciência da Informação também abarcou essas questões.

Na área da Ciência da Informação dois trabalhos de Andrade (1989) e Thiesen (1997) podem ser apontados como pioneiros no tema da relação entre memória e informação no contexto da ditadura brasileira. Cardoso investiga os Centros de Documentação e de Comunicação Popular (CDCPs) que atuavam, entre 1970-80, como espaços de resistência à ditadura e demonstra o papel fundamental que tiveram na produção e organização de informação relativa à atuação e a memória dos movimentos sociais. Em sua tese (defendida em 1997 e publicada em 2013) Icléia Thiesen desenvolve o conceito de memória institucional para pensar a institucionalização da Ciência da Informação. Em um capítulo específico a autora correlaciona memória, esquecimento e informação para pensar contextos traumáticos como os da ditadura e da anistia brasileiras. Thiesen questiona então

A anistia é o esquecimento oficial de acontecimentos passados, que institucionaliza uma espécie de perdão. [...]. Mas perguntamos, o fato de ter havido anistia significa que os fatos objeto da anistia foram realmente esquecidos? [...] A história mostra que não. A história molda e subverte a memória coletiva, numa relação de permanente tensão. A memória é fonte da história, mas também instrumento de resistência. (THIESEN, 2013, p. 257).

Thiesen posteriormente amplia a temática e abre um campo para publicações sobre documentos sensíveis, documentos da repressão e da resistência (THIESEN, 2014; FROTA, 2017; THIESEN et al., 2017). No tema documentos sensíveis cabe também destacar as publicações de Georgete Rodrigues $(2008 ; 2009)$ que possibilitam uma abordagem tanto na perspectiva da Ciência da Informação quanto da arquivologia.

No contexto transicional, a implementação das comissões relativas às violações de direitos humanos (Comissão de Mortos e Desaparecidos Políticos em 1995, Comissão de Anistia em 2002 e Comissão Nacional da Verdade em 2014) e a aprovação de legislação relativa ao acesso à informação e aos arquivos impulsionaram pesquisas na Ciência da Informação e na Arquivologia. Essas pesquisas têm como foco a documentação produzida por organismos repressivos e por organizações de resistência às ditaduras e os arquivos nos quais estão guardados os documentos.

Para uma visão geral sobre a produção relativa às memórias da repressão e da resistência na Ciência da Informação elaborou-se dois levantamentos um de teses e dissertações (Quadro 1) e outro de artigos de periódicos (Quadro 2).

Quadro 1-Teses e dissertações em Ciência da Informação/Memórias da Repressão

\begin{tabular}{c|c|c|c|c|c}
\hline \multicolumn{7}{c}{ Teses e Dissertações } \\
\hline Título & Autor & Orientador & Instituição & Programa & Data \\
\hline \hline
\end{tabular}

${ }^{5}$ Dados dos quadros coletados pela bolsista de iniciação científica (PROBIC/FAPEMIG) Olívia Coimbra. 


\begin{tabular}{|c|c|c|c|c|c|}
\hline \multicolumn{6}{|c|}{ Teses e Dissertações } \\
\hline Título & Autor & Orientador & Instituição & Programa & Data \\
\hline $\begin{array}{l}\text { Tese - Memórias clandestinas e } \\
\text { sua museificação: uma } \\
\text { prospecção sobre } \\
\text { institucionalização e agregação } \\
\text { informacional }\end{array}$ & $\begin{array}{l}\text { Castro, Ana } \\
\text { Lúcia Siaines } \\
\text { de }\end{array}$ & $\begin{array}{l}\text { Marteleto, } \\
\text { Regina } \\
\text { Maria }\end{array}$ & $\begin{array}{l}\text { Universidade Federal } \\
\text { do Rio de Janeiro / } \\
\text { Instituto Brasileiro de } \\
\text { Informação em Ciência } \\
\text { e Tecnologia }\end{array}$ & $\begin{array}{l}\text { Programa de Pós- } \\
\text { Graduação em } \\
\text { Ciência da } \\
\text { Informação }\end{array}$ & 2002 \\
\hline $\begin{array}{l}\text { Dissertação - A vontade da } \\
\text { verdade, a informação e o arquivo }\end{array}$ & $\begin{array}{l}\text { Elias, Aluf } \\
\text { Alba V. }\end{array}$ & $\begin{array}{l}\text { González de } \\
\text { Gómez, } \\
\text { Maria Nélida }\end{array}$ & $\begin{array}{l}\text { Universidade Federal } \\
\text { do Rio de Janeiro / } \\
\text { Instituto Brasileiro de } \\
\text { Informação em Ciência } \\
\text { e Tecnologia }\end{array}$ & $\begin{array}{l}\text { Programa de Pós- } \\
\text { Graduação em } \\
\text { Ciência da } \\
\text { Informação }\end{array}$ & 2012 \\
\hline $\begin{array}{l}\text { Dissertação - Comissão da } \\
\text { verdade: os documentos e a } \\
\text { validez do discurso }\end{array}$ & $\begin{array}{l}\text { Côrbo, Dayo } \\
\text { de Araújo } \\
\text { Silva }\end{array}$ & $\begin{array}{l}\text { Lima, Clovis } \\
\text { Montenegro } \\
\text { de }\end{array}$ & $\begin{array}{l}\text { Universidade Federal } \\
\text { do Rio de Janeiro / } \\
\text { Instituto Brasileiro de } \\
\text { Informação em Ciência } \\
\text { e Tecnologia }\end{array}$ & $\begin{array}{l}\text { Programa de Pós- } \\
\text { Graduação em } \\
\text { Ciência da } \\
\text { Informação }\end{array}$ & 2013 \\
\hline $\begin{array}{l}\text { Tese - Produção de sentido em } \\
\text { documentos e informações de } \\
\text { arquivos sigilosos: comunidade } \\
\text { de informação e contrainformação } \\
\text { sob o olhar da Assessoria de } \\
\text { Segurança e Informação - ASI } \\
\text { UFF de } 1971 \text { - } 1982\end{array}$ & $\begin{array}{l}\text { Souza, } \\
\text { Rosale de } \\
\text { Mattos }\end{array}$ & $\begin{array}{l}\text { Pimenta, } \\
\text { Ricardo } \\
\text { Medeiros }\end{array}$ & $\begin{array}{l}\text { Universidade Federal } \\
\text { do Rio de Janeiro / } \\
\text { Instituto Brasileiro de } \\
\text { Informação em Ciência } \\
\text { e Tecnologia }\end{array}$ & $\begin{array}{l}\text { Programa de Pós- } \\
\text { Graduação em } \\
\text { Ciência da } \\
\text { Informação }\end{array}$ & 2017 \\
\hline
\end{tabular}

Fonte: Biblioteca Digital Brasileira de Teses e Dissertações (BDTD). Disponível em: <http://bdtd.ibict.br/>. Acesso em: 28 nov. 2018.

Em relação às teses e dissertações constata-se que a produção é restrita, recente e está concentrada em dois programas, ambos no Rio de Janeiro. Ressaltava-se que o levantamento é preliminar e não exaustivo ou que parte da produção pode ainda não ter sido indexada.

\section{Quadro 2- Artigos de periódicos em Comunicação e Ciência da Informação (Qualis CAPES)}

\begin{tabular}{|c|c|c|c|c|}
\hline \multicolumn{5}{|c|}{ Artigos de periódicos } \\
\hline Título & Autor & Periódico & Classificação Qualis & Data \\
\hline $\begin{array}{l}\text { O valor da informação: um desafio } \\
\text { permanente }\end{array}$ & $\begin{array}{l}\text { Castro, Ana Lúcia } \\
\text { Siaines de }\end{array}$ & $\begin{array}{l}\text { DataGramaZero, n. } 3 \text {, } \\
\text { v. } 3\end{array}$ & $\begin{array}{l}\text { Qualis CAPES - } 2016 \text { - } \\
\text { Comunicação e } \\
\text { Informação: B1 }\end{array}$ & 2002 \\
\hline $\begin{array}{l}\text { A Ditadura Documentada: Acervos } \\
\text { desclassificados do regime militar } \\
\text { brasileiro }\end{array}$ & Fico, Carlos & $\begin{array}{l}\text { Acervo - Revista do } \\
\text { Arquivo Nacional, n. } \\
\text { 2, v. } 21\end{array}$ & $\begin{array}{l}\text { Qualis CAPES - } 2016 \text { - } \\
\text { Comunicação e } \\
\text { Informação: B2 }\end{array}$ & 2008 \\
\hline $\begin{array}{l}\text { Os Arquivos do Centro de } \\
\text { Informações do Exterior (CIEX): O } \\
\text { elo perdido da repressão }\end{array}$ & Penna Filho, Pio & $\begin{array}{l}\text { Acervo - Revista do } \\
\text { Arquivo Nacional, n. } \\
\text { 2, v. } 21\end{array}$ & $\begin{array}{l}\text { Qualis CAPES - } 2016 \text { - } \\
\text { Comunicação e } \\
\text { Informação: B2 }\end{array}$ & 2008 \\
\hline $\begin{array}{l}\text { Do Direito de Saber: O acesso à } \\
\text { informação pessoal privada nos } \\
\text { arquivos da ditadura militar brasileira }\end{array}$ & Carrara, Sérgio & $\begin{array}{l}\text { Acervo - Revista do } \\
\text { Arquivo Nacional, n. } \\
\text { 1, v. } 24\end{array}$ & $\begin{array}{l}\text { Qualis CAPES - } 2016 \text { - } \\
\text { Comunicação e } \\
\text { Informação: B2 }\end{array}$ & 2011 \\
\hline $\begin{array}{l}\text { Legislação de Acesso aos Arquivos } \\
\text { no Brasil: Um terreno de disputas } \\
\text { políticas pela memória e pela história }\end{array}$ & $\begin{array}{l}\text { Rodrigues, } \\
\text { Georgete Medleg }\end{array}$ & $\begin{array}{l}\text { Acervo - Revista do } \\
\text { Arquivo Nacional, n. } \\
\text { 1, v. } 24\end{array}$ & $\begin{array}{l}\text { Qualis CAPES - } 2016 \text { - } \\
\text { Comunicação e } \\
\text { Informação: B2 }\end{array}$ & 2011 \\
\hline
\end{tabular}




\section{Artigos de periódicos}

\begin{tabular}{|c|c|c|c|c|}
\hline Título & Autor & Periódico & Classificação Qualis & Data \\
\hline $\begin{array}{l}\text { O dever de memória e a } \\
\text { documentação sobre a ditadura civil- } \\
\text { militar na Universidade Federal do } \\
\text { Pará (UFPA) }\end{array}$ & $\begin{array}{l}\text { Fontes, Edilza } \\
\text { Joana Oliveira }\end{array}$ & $\begin{array}{l}\text { Acervo - Revista do } \\
\text { Arquivo Nacional, n. } \\
\text { 1, v. } 27\end{array}$ & $\begin{array}{l}\text { Qualis CAPES - } 2016 \text { - } \\
\text { Comunicação e } \\
\text { Informação: B2 }\end{array}$ & 2014 \\
\hline $\begin{array}{l}\text { Fontes sobre as organizações de } \\
\text { resistência à ditadura civil-militar no } \\
\text { Brasil: caracterização e possibilidades } \\
\text { de investigação }\end{array}$ & $\begin{array}{l}\text { Gasparotto, } \\
\text { Alessandra }\end{array}$ & $\begin{array}{l}\text { Acervo - Revista do } \\
\text { Arquivo Nacional, n. } \\
\text { 1, v. } 27\end{array}$ & $\begin{array}{l}\text { Qualis CAPES - } 2016 \text { - } \\
\text { Comunicaçãa e } \\
\text { Informação: B2 }\end{array}$ & 2014 \\
\hline $\begin{array}{l}\text { A memória sem medo: sobre o resgate } \\
\text { de pessoas e documentos das garras } \\
\text { da ditadura }\end{array}$ & Ciavatta, Maria & $\begin{array}{l}\text { Acervo - Revista do } \\
\text { Arquivo Nacional, n. } \\
\text { 1, v. } 27\end{array}$ & $\begin{array}{l}\text { Qualis CAPES - } 2016 \text { - } \\
\text { Comunicaçãa e } \\
\text { Informação: B2 }\end{array}$ & 2014 \\
\hline $\begin{array}{l}\text { Empresas, ditadura civil militar } \\
\text { brasileira e centros de memória e } \\
\text { documentação corporativos: um } \\
\text { estudo exploratório. }\end{array}$ & $\begin{array}{l}\text { Costa, Alessandra } \\
\text { de Sá Mello da; } \\
\text { Silva, Marcelo } \\
\text { Almeida de } \\
\text { Carvalho; } \\
\text { Monteiro, Carlos } \\
\text { Arthur Vieira }\end{array}$ & $\begin{array}{l}\text { Logeion: filosofia da } \\
\text { informação, n. 1, v. } 2\end{array}$ & $\begin{array}{l}\text { Qualis CAPES - } 2016 \text { - } \\
\text { Comunicação e } \\
\text { Informação: B5 }\end{array}$ & 2015 \\
\hline $\begin{array}{l}\text { Transparência no acesso à informação } \\
\text { e as memórias virtuais da ditadura } \\
\text { militar no site Brasil: Nunca mais } \\
\text { Digit@1 }\end{array}$ & $\begin{array}{l}\text { Massoni, Luis } \\
\text { Fernando Herbert; } \\
\text { Morigi, Valdir } \\
\text { Jose; Engelmann, } \\
\text { Solange Inês; } \\
\text { Viana, Arthur } \\
\text { Walber }\end{array}$ & $\begin{array}{l}\text { Biblionline; Joao } \\
\text { Pessoa Vol. 11, Ed. } 1\end{array}$ & $\begin{array}{c}\text { Qualis CAPES - } 2016 \text { - } \\
\text { Comunicação e } \\
\text { Informação: B5 }\end{array}$ & 2015 \\
\hline $\begin{array}{l}\text { O acesso à informação e o parlamento } \\
\text { brasileiro: estudo sobre a produção } \\
\text { legislativa no período da ditadura } \\
\text { militar(1964-1985) }\end{array}$ & $\begin{array}{l}\text { Silva, Terezinha } \\
\text { Elizabeth da; } \\
\text { Eirão, Thiago } \\
\text { Gomes; Santos } \\
\text { Junior, Ernani } \\
\text { Rufino dos; } \\
\text { Cavalcante, } \\
\text { Raphael da Silva; } \\
\text { Garcia, Laís } \\
\text { Lorena Barbosa } \\
\end{array}$ & $\begin{array}{l}\text { Perspectivas em } \\
\text { Ciência da } \\
\text { Informação, n. } 4, \mathrm{v} . \\
22\end{array}$ & $\begin{array}{l}\text { Qualis CAPES - } 2016 \text { - } \\
\text { Comunicação e } \\
\text { Informação: A1 }\end{array}$ & 2017 \\
\hline $\begin{array}{l}\text { Arquivos da repressão: fontes de } \\
\text { informação sobre diversidade sexual e } \\
\text { de gênero na ditadura militar }\end{array}$ & $\begin{array}{l}\text { Cabral, Jacqueline } \\
\text { Ribeiro }\end{array}$ & Archeion Online, v. 5 & $\begin{array}{l}\text { Qualis CAPES - } 2016 \text { - } \\
\text { Comunicaçãa e } \\
\text { Informação: C }\end{array}$ & 2017 \\
\hline $\begin{array}{l}\text { Filmografia sobre frei Tito: o } \\
\text { audiovisual como documento } \\
\text { memorialístico }\end{array}$ & $\begin{array}{l}\text { Almeida, Mariana } \\
\text { Zampier de; } \\
\text { Assis, João } \\
\text { Marcus } \\
\text { Figueiredo }\end{array}$ & $\begin{array}{l}\text { Informação } \\
\text { Arquivística, n. 2, v. } 6\end{array}$ & $\begin{array}{l}\text { Qualis CAPES - } 2016 \text { - } \\
\text { Comunicaçãa e } \\
\text { Informação: B5 }\end{array}$ & 2017 \\
\hline $\begin{array}{l}\text { Rosas de Chumbo: da censura e sigilo } \\
\text { ao acesso de documentos da ditadura } \\
\text { brasileira }\end{array}$ & $\begin{array}{l}\text { Salcedo, Diego; } \\
\text { Costa, Luana } \\
\text { Alves de Melo }\end{array}$ & $\begin{array}{l}\text { Informação \& } \\
\text { informação; Londrina } \\
\text { Vol. 23, Ed. } 2\end{array}$ & $\begin{array}{l}\text { Qualis CAPES - } 2016 \text { - } \\
\text { Comunicação e } \\
\text { Informação: A2 }\end{array}$ & 2018 \\
\hline $\begin{array}{l}\text { Livros proibidos pelo sr. Ministro da } \\
\text { Justiça }\end{array}$ & $\begin{array}{l}\text { Igreja, Paula } \\
\text { Ribeiro Da }\end{array}$ & $\begin{array}{l}\text { Múltiplos Olhares em } \\
\text { Ciência da } \\
\text { Informação, n. } \\
\text { Especial }\end{array}$ & $\begin{array}{c}\text { Qualis CAPES - } 2016 \text { - } \\
\text { Comunicação e } \\
\text { Informação: B5 }\end{array}$ & 2018 \\
\hline $\begin{array}{l}\text { As recomendações das comissões da } \\
\text { verdade no Brasil sobre os arquivos } \\
\text { da ditadura militar (1964- 1985): uma } \\
\text { análise dos relatórios finais }\end{array}$ & $\begin{array}{l}\text { Tenaglia, Mônica; } \\
\text { Rodrigues, } \\
\text { Georgete Medleg }\end{array}$ & $\begin{array}{l}\text { Em Questão, n. 2, v. } \\
24\end{array}$ & $\begin{array}{l}\text { Qualis CAPES - } 2016 \text { - } \\
\text { Comunicação e } \\
\text { Informação: A2 }\end{array}$ & 2018 \\
\hline Nas correntes da ditadura & $\begin{array}{l}\text { Botácio, Andrieli } \\
\text { Cristina; Ferreira, } \\
\text { Bruna Letícia; } \\
\text { Carneiro, Marília }\end{array}$ & $\begin{array}{l}\text { Múltiplos Olhares em } \\
\text { Ciência da } \\
\text { Informação, } \mathrm{n} \text {. } \\
\text { Especial }\end{array}$ & $\begin{array}{l}\text { Qualis CAPES - } 2016 \text { - } \\
\text { Comunicação e } \\
\text { Informação: B5 }\end{array}$ & 2018 \\
\hline
\end{tabular}


Artigos de periódicos

\begin{tabular}{c|l|c|c|c}
\hline Título & \multicolumn{1}{|c|}{ Autor } & Periódico & Classificação Qualis & Data \\
\hline \hline & Soares; & & & \\
& Bernardino, & & & \\
& Neuza Fujiko; & & & \\
& Pereira, Tiago & & & \\
& Martins & & & \\
\end{tabular}

Fonte: Base de Dados em Ciência da Informação (BRAPCI). Disponível em:

$<$ http://bdtd.ibict.br/>; Library and Information Science Abstracts (LISA). Acesso em:

28 nov. 2018.

Em relação aos artigos a principal constatação é que o periódico com mais publicações (7 das 17 identificadas) é o "Acervo-Revista do Arquivo Nacional", o que provavelmente se explica pela centralidade dessa instituição em importantes conjunturas, a saber: nos processos de elaboração da Lei de Arquivos (1995) e da Lei de Acesso à Informação (2011) e no aporte ao trabalho da Comissão Nacional da Verdade (201114). O Projeto Memórias Reveladas ${ }^{6}$ desenvolvido pelo Arquivo Nacional para recolher e disponibilizar os documentos das instituições ligadas ao sistema repressivo durante a ditadura militar (SNI, CIEX, dentre outros) foi central para a CNV. Ressalva-se que esse levantamento também é preliminar e não exaustivo.

\section{Considerações finais}

No âmbito das temáticas que correlacionam informação e direitos humanos no plano internacional, considera-se que a atuação da Ciência da Informação ainda é restrita. Mas, percebe-se também que os complexos desafios postos para a efetivação das convenções de direitos humanos suscitam problemáticas que são específicas desse campo de conhecimento e que, portanto, demandam uma ampliação de pesquisas. Ressalva-se, no entanto, que essas considerações não estão pautadas em levantamento bibliográfico exaustivo, mas em levantamentos vinculados às pesquisas mencionadas, desenvolvidas pela autora e orientandos, entre 2007 e 2017. O desenvolvimento de pesquisas nessa temática pode contribuir principalmente para o aperfeiçoamento dos processos de monitoramento da implementação de convenções internacionais de direitos humanos.

No âmbito das temáticas relativas às memórias da repressão e da resistência a Ciência da Informação assim como a Biblioteconomia e a Arquivologia têm importantes questões de investigação a serem exploradas, questões que fazem fronteira com a história e o direito e que demandam, portanto, um aporte interdisciplinar. O desenvolvimento dessas pesquisas pode contribuir principalmente com a compressão das possibilidades, limites e desafios que permeiam os processos de guarda e de publicização dos documentos sensíveis, em distintos regimes e conjunturas mais ou menos democráticos.

6 BRASIL. Arquivo Nacional. Memórias reveladas. Cronologia. Disponível em: <http://www.memoriasreveladas.arquivonacional.gov.br/cgi/cgilua.exe/sys/start.htm?infoid=3\&sid=2>. Acesso em: 28 nov. 2018. 


\section{Referências}

ALVES, M. H. M. Estado e oposição no Brasil (1964-1984). Petrópolis: Vozes, 1984.

ANDRADE, A. M. C. de. Um novo texto no contexto da informação popular: os centros de documentação. 1989. 202f. Tese (Doutorado em Ciências da Comunicação) - Escola de Comunicação e Artes, Universidade de São Paulo, São Paulo, 1989.

ARNS, P. E. Brasil: nunca mais. 2. ed. Petrópolis: Vozes, 1985.

BARBOSA NETO, P. A. Fluxos informacionais para o monitoramento da implementação da Convenção 182 da Organização Internacional do Trabalho sobre as piores formas do trabalho infantil. 2013. 261f. Tese (Doutorado em Ciência da Informação) - Escola de Ciência da Informação, Universidade Federal de Minas Gerais, Belo Horizonte, 2013.

BRASIL. Arquivo Nacional. Cronologia. Memórias Reveladas. Disponível em:

$<$ http://www.memoriasreveladas.arquivonacional.gov.br/cgi/cgilua.exe/sy s/start.htm?infoid=3\&sid=2 >. Acesso em: 20 nov. 2018.

COMISIÓN PROVINCIAL POR LA MEMORIA. Archivo DIPBA. Disponível em: $<$ http://www.comisionporlamemoria.org/cuadroclasificacion/\#seccion12>. Acesso em: 20 nov. 2018.

COMISIÓN NACIONAL SOBRE LA DESAPARICIÓN DE PERSONAS (CONADEP). Nunca Más: informe de la Comisión Nacional sobre la Desaparición de Personas. Buenos Aires: Eudeba, 2014.

CRENZEL, E. La historia política del Nunca Más: la memoria de las desapariciones en la Argentina. Buenos Aires: Siglo Veintiuno Editores, 2014.

FROTA, M. G. da C. A convenção dos direitos da criança e os desafios para sua implementação nos países sul-americanos. Revista do Observatório do Milênio, Belo Horizonte, v. 1, p. 93-106, 2008.

FROTA, M. G. da C. Political and legal effects of the Convention on the Rights of the Child in Latin American Countries. In: BASS, L.; KINNEY, D. (Org.). The well-being, peer cultures and rights of children. Bingley: Emerald Group, 2011. v. 14, p. 307-323.

FROTA, M. G. da C. Memória e registro das violações aos direitos da criança nos documentos da Corte Interamericana de Direitos Humanos. Pesquisa Brasileira em Ciência da Informação e Biblioteconomia, João Pessoa, v. 9, n. 2, p. 1-13, 2014.

FROTA, M. G. da C. Memórias da repressão e da resistência: um olhar comparado entre Brasil e Argentina. Revista Informação na Sociedade Contemporânea, Natal, v. 1, n. 2, p. 1-18, 2017.

FROTA, M. G. da C. Políticas de memória e arquivos da repressão e da resistência: desafios para o acesso à informação pública na Argentina e no 
Brasil. In: ENCONTRO DA ASSOCIAÇÃO DE EDUCAÇÃO E PESQUISA EM CIÊNCIA DA INFORMAÇÃO DA IBERO-AMÉRICA E CARIBE, 10., 2016, Belo Horizonte. Anais [...] Belo Horizonte: ECI/UFMG, 2016. Disponível em: <http://edicic2016.eci.ufmg.br/anais/\#modal>. Acesso em: 28 out. 2018

FROTA, M. G. da C.; BARBOSA NETO, P. A. Mediação institucional e processo socioinformacional de monitoramento dos direitos da criança no sistema mundial. DataGramaZero, Rio de Janeiro, v. 6, n. 1, p. 1-10, 2011.

FROTA, M. G. da C.; BARBOSA NETO, P. A. Parameters and procedures of the interamerican system in children's rigths violation lawsuits. Revista de Direito Internacional, Brasília, v. 10, n. 2, p. 316-333, 2013.

FROTA, M. G. da C.; RIBEIRO, A. C.; GOMES, P. A qualidade do Tesauro da Corte Interamericana de Direitos Humanos como instrumento de organização da informação e do conhecimento. In: PINHO, F. A.; GUIMARÃ̃ES, J. A. C. (Org.). Memória, tecnologia e cultura na organização do conhecimento. Recife: Editora UFPE, 2017. v. 4, p. 225-232. E-book.

FROTA, M. G. da C.; QUINTÃO, P. G. An analysis on the implementation of the Convention on the rights of the child in south american and eurupean countries. Pensamiento Juridico, Bogotá, v. 19, p. 175-190, 2007.

JELIN, E. Los trabajos de la memoria. Madrid: SIGLO XXI, 2002.

MOURA, M. A. M. (Org.). A construção social do acesso público à informação no Brasil. Belo Horizonte: Editora UFMG, 2014.

NORA, P. Entre memória e história: a problemática dos lugares. Projeto História, São Paulo, v. 10, jul./dez. 1993.

POLLAK, M. Memória, esquecimento e silêncio. Estudos históricos, Rio de Janeiro, v. 2, n. 3, p. 3-15, 1989.

RABOTNIKOF, N. Memoria política a treinta años del golpe. In: LIDA, C. E.; CRESPO, H.; YANLEVICH, P. (Comp.). Argentina 1976: estudios em torno el golpe de estado. México: El Colégio de México, 2006.

RIBEIRO, A. C. A produção científica em direitos humanos nos países do sul global: uma análise bibliométrica e cinetométrica da Sur Revista Internacional de Direitos Humanos. 2016. 123f. Dissertação (Mestrado em Ciência da Informação) - Escola de Ciência da Informação, Universidade Federal de Minas Gerais, Belo Horizonte, 2016.

RIBEIRO, A. C.; FROTA, M. G. da C. A produção científica em Direitos Humanos nos países do Sul Global: uma análise bibliométrica e cientométrica da Sur Revista Internacional de Direitos Humanos. In: ENCONTRO NACIONAL DE PESQUISA EM CIÊNCIA DA INFORMAÇÃO. 18., 2017, Marília. Anais [...] Marília: UNESP, 2017. Disponível em: <http://enancib.marilia.unesp.br/index.php/xviiienancib/ENANCIB/schedC onf/presentations>. Acesso em: 28 out. 2018

RICOEUR, P. A memória, a história, o esquecimento. Campinas: UNICAMP, 2007. 
RODRIGUES, G. M. Mémoire et secret: le cas Herzog et les archives de la dictature militaire au Brésil. Revista Arhivelor, Frankfurt: CEEOL, v. 88, p. 87-100, 2008.

RODRIGUES, G. M. Arquivos, anistia política e justiça de transição no Brasil: onde os nexos? Revista Anistia Política e Justiça de Transição, Brasília: Ministério da Justiça, n. 1, p. 136-151, jan./jun. 2009.

SANTOS, M. S. dos. Memória coletiva e teoria social. São Paulo: Annablume, 2003.

SARLO, B. Tempo passado: cultura da memória e guinada subjetiva. São Paulo: Companhia das Letras; Belo Horizonte: Editora UFMG, 2007.

SILVA, S. L.; FROTA, M. G. da C. Dimensões do acesso aos arquivos do Departamento de Ordem Política e Social do Estado de Minas Gerais. Perspectivas em Ciência da Informação (Impresso), v. 14, n. esp., p. 105$119,2009$.

SOBRE nós. In: Brasil: nunca mais digit@l. 2016. Disponível em: $<$ http://bnmdigital.mpf.mp.br/pt-br/sobre.html $>$. Acesso em: 28 out. 2018

THIESEN, I. Documentos sensíveis: informação, arquivo e verdade na ditadura de 1964. Rio de Janeiro: 7Letras, 2014.

THIESEN, I. Memória institucional. João Pessoa: Editora UFPB, 2013.

THIESEN, I. Memória institucional: a construção conceitual numa abordagem teórico-metodológica. 1997. 169f. Tese (Doutorado em Ciência da Informação) - Universidade Federal do Rio de Janeiro; Instituto Brasileiro de Informação em Ciência e Tecnologia, Rio de Janeiro, 1997.

THIESEN, I.; RODRIGUES, G. M.; FROTA, M. G. da C.; ALMEIDA, P. C. Ciência da Informação, História e Política. Pesquisa Brasileira em Ciência da Informação e Biblioteconomia, João Pessoa, v. 12, n. 2, p. 360-378, 2017. 